\title{
Two illustrations from South Korea and some reflections about the public administration studies: Are we granted to pillory the ethics or social justice?
}

\author{
Kiyoung Kim \\ College of Law, Chosun University, Kwang-ju, South Korea
}

Email address:

KiyoungKim@chosun.ac.kr

\section{To cite this article:}

Kiyoung Kim. Two Illustrations from South Korea and Some Reflections about the Public Administration Studies: Are We Granted to Pillory the Ethics or Social Justice. International Journal of Philosophy. Vol. 2, No. 4, 2014, pp. 48-59. doi: 10.11648/j.ijp.20140204.11

\begin{abstract}
Amidst the ideology, efficiency and bitter contention of international economy, the importance of leadership or public administration had long been under-stressed as an avenue for any better solution. Nonetheless, within a changing mode of interaction in the global community, an increasing ethos for the kind of common basis of ethics or agreement, at least in the level of class administrators or noble citizenry including the academicians, business leaders, bureaucrats and so, could be congruent for the public good on the national and international plane. A rapid transformation for the informative society or sharing and humanity or social justice generally is seen to enable the possibility of new openness against the divergences from various reasons. Typically, I consider the public administration other than law, inter alia, could have strands to leap for any grand promise or for any cosmopolitan public value since it tends progressive and less ideological. At the core of ambition underlie the ethics of public administrators or their responsibility for the constituents and global public. The paper deals with two illustrative cases from the experience of South Korea which matters at the negative and positive concept of liberty. They will be investigated, empirically at some extent and in view of the ethics of congressmen and public officers. I, then, turn to explore the western theories and tenets often associated with their moral standard. Finally, the context could be revisited for the global scale of transformation expanded to cover the Orient and West.
\end{abstract}

Keywords: Public administration, National Assembly, Congressman, Ethics, Political Theories, Orient and West, South Korea, Positive Liberty, Social Justice

\section{The National Assembly of Korea and Nature of Organization}

I chose the National Assembly of South Korea (NASK) for the purpose of this article, and shall apply the hypothesis as well as typology of ethical analysis on philosophies and scores of ethical virtue. This work would include the ethical challenges seriously debated in the near past and present days of NASK. As a public policy student, I intend to frame recommendations to produce a better picture to resolve the conflict of ethics, and explore factors to affect an implementation (Hicks, D., 2013). I finally draw upon the outcome with suggestions. While linking the two cases with the philosophies and theories to ground an intelligent basis of public administrators, I will discuss two implications, say, the ethics and responsible administration within the collegiate body as well as new orientation of academic response to the changing world politics, economics and society

The NASK has long been an indispensable organ incorporated within the Korean constitution since 1948, and the practice or institutional tradition can be shared as same within the universal context. Even if the parliamentary system of government may be discarded by the constitutional drafters as in the Korean case, the assembly body, mutas mutandis, the Congress or Parliament would sustain the public governance. This tradition would perhaps be stronger as in the Socialist states, for example the Duma or National People's Congress of People's Republic of China. In a suggestion later drawn to bridge the Orient and West or Socialist to Liberal by focusing on the ethics of 
ruling class or social justice, it bears a perceptive implication that the NASK operates as a collegiate body (Laureate Education Inc. a, 2013). This implies that the collegiate body, as structured within the constitutions, is indispensable and centralized in public administration. The NASK can well be viewed to mostly share the universal qualities and attributes when we surf onto other global bodies in any comparative politics or constitutional study. It is chaptered in the first of government structure from the Korean Constitution, which deals with such, including the elected congressman, exclusive legislative power and supervisory role to monitor other governmental branches, privileges and immunities ascribed to the members, the fixed constitutional term on their service, restrictions in double-posting and so.

According to the Constitution, the election will be held in four years to reshuffle a previous body and for the new term. The last election was held in 2012, and was denoted as the $19^{\text {th }}$ congress in the constitutional history of Korea. The election requires the members directly chosen by the people, but some quota basis approach was introduced to assign the members based on the total number of vote for the respective political party. Sanenouri, the ruling party of Korea, had been successful to achieve a majority status in the last election. Minjoo (democratic party in English), the major opposing party, also acquired a fair number of seats which became able to influence their political ethos and goal. Some groups may like to explore the constitutional reform, which advocate the parliamentary system of government, but merely hover around the academics or distinct group of politicians. The NASK currently operates under the 1987 Constitution based on the presidential system, and the chance to transform would largely be seen improbable in any recent years. Hence, NASK is generally considered to execute their constitutional mandate on the separation of powers principle, which only takes a part to integrate the national policy, neither a center of government unlike the parliamentary system. However, the party system often dominant in the contemporary politics would mediate the president and NASK, which also would be a case in Korea. As the social justice and virtue of Republican democracy still largely are the factors of political contention despite the commonalities and divergences over history, the type of collegiate body would certainly be the forum where the nature and state of social justice issues in a specific national polity are to be debated (SEP : Economics and Economic Justice, 2013). This would not be an exception in Korea. While Korea has practiced the constitutional democracy since 1948, the NASK often had been less powerful in some sense or below its expected role in the Republican democracy or liberal politics. This means that it had, most of times, generally been seen a feeble institution under the kind of charismatic presidents. From his personal background, Seung Man Lee had been strong as a national leader of independence from the Japanese imperial rule. He had a hereditary affinity with the Chosen dynasty and one of most enlightened intellectuals educated in the US. Chung-hee Park also ruled in any absolute hierarchy beyond the congressional check and balance, which had a root basis in his militaristic might and growing quest to national industrialization and economic development. Chun Doo-hwan, who had reigned during 1981-1988 and Roh Tae-woo, one of his protégé, would largely be disposed in some similar fashion, who ruled the country in his personified way. The constitutional institution and system were neglected or disregarded, and the personal network prevailed. It is, however, interesting that the theme of social justice, in his period of rule, made a debut in the Korean politics, at least in the parlance of government owing to the growing status of national economy (2013). The role and performance of NASK, therefore, largely depends on the constitutional system and political culture in a specific country. In this respect, the NASK, which could be considered as leveled with the western counterpart in its culture and performance, has truly begun after the 1987 constitutional reform and Roh Tae-woo's administration.

\section{Two Ethical or Societal Issues}

\subsection{Around and the First Case}

For the purpose of illustration, let me pick up two issues which possess the different characteristics in terms of the classic liberty and nearer concept of social rights (Universal Declaration of Human Rights, 2013; Crocker, L.H., 1980; SEP: Positive and Negative Liberty, 2013). The first example, contended in view of the ethics or social justice, aroused a public attention about the conflict of interest (Hicks, D., 2013). It poses the challenge, in an analogous context, concerning many issues and agendas of ethics and administration, such as Russian Mafia or Chinese trauma of corruption, although its substance involves a small ambit of national pension for the retired congressmen. Therefore, an ethical dilemma of the issue exhibits a good aspect of discussion about the liberty, equality and social justice, particularly from a perception about the ways of operation within the collegiate bodies (Cooper, T., 2012). The second example developed in the context of municipal program concerning the child subsidies. Seoul city, in the initiative to promote the political philosophy and social justice, has endeavored on the program, which now faces a difficulty from the worse national budget. The issue progressed contentiously and in any intensity of public controversy, which had both of voice, say, public criticism and progressive activism. It shows a fine context of political interplay, the concern of which spans over the role and responsibility between the national and local government, as well as the political ideals both major parties engineer in continuance. A contention and disagreement on this issue had fueled an intense public debate in the mayor election, and no candidate would be convinced of his unwavering probabilities about winning the election. This would go as same in the 2014 local election since the program also was 
not supported this year by the national budget.

The Pension Program for the National Assemblyman in Korea (PPNAM) was pursued around 2009, and the statute has passed in Mar. 2010. Since 2013, an implantation was secured through the 2013 national budget approved by the national assembly. The official title of statute to ground the PPNAM is the Supportive Act of Democratic Constitutional Rule in the Republic of Korea (SADCRRK, 2013). The Act provides in its pertinent article, "the National and Local Government would grant the subsidies in the purpose to meet the cost and fund which are deemed necessary to support the operation of Democratic Constitutional Association and its senior members above the age of 65 (2013). To put it simply, the goals of statute have been intended to support the former and standing congressmen, who exclusively could enter the Association and obtain its membership. So it has the nature of seniority pension program on the condition of its membership, in which one chance of successful candidacy and qualification as a congressman could satisfy the requirement of statute.

\subsection{The Second Case}

Other ethical issue for the National Assembly involves the Free Fostering Plan of Child (FFCP), which has led to a serious public debate about the social justice and feasibility of plan (AECFP, 2013). There had been factors to affect an implementation, for example, excessive budget or irrationalities from the unrefined system (Cooper, T., 2012). Often it was put in contrast between the opposing party, Minjoo, and conservatives, Saenuori. As the local election for the Seoul mayor profiles so high in view of Korean politics, the parties most always do their best to attract the voters and persuade on their strengths of public policy. Seoul citizens often are an educated intellectual who can assess the policy issues and their consequence, who account for one fourth of national populace. Seoul is also the province of contention with a half-to-half cut between two parties leading to any decisive margin for key national elections, such as the Presidential and National Assembly. The Plan particularly got to be problematic since Seoul also is required to be responsible for many social programs including the Free Food Program for the Middle and High Schools and because of its pressing political gravity between the two parties (Korea JoongAng Daily, 2013). I now brief on the feature of that programs, the issues and challenges, points of assessment as well as factors to affect an implementation of both Plans.

\section{Key Social Justice Themes}

\subsection{The First Case}

The ethical dilemma of this program contributes to the worse public sentiment as it is problematic in view of the public conscience and reason (Chosun Daily, 2013). The kind of program was not unique in Korea, but a scope of developed countries enacted and implemented such policy.
They generally are considered, however, as designed reasonably and in the permissible fashion. US, UK, Germany and France could come within this class, and Japan has recently abolished the system. PPNAMs in these countries mandate a stern classification about the eligibility to pension money, and the sum was not fixed unlike Korea. It maintains, however, a sliding system on the calculation method which pertains with specificity. Let me tender an extent of its flaws and weaknesses. First, the scope of eligibility is rather comprehensive and generous to disable a prudent assessment about the merit. The Act provides ten disqualifying causes in this end, yet to be insufficient because of its ambiguities and catch-all dealings inoperable to exclude an impertinent beneficiary. The practical consequence of this flaw would be that the assemblymen can claim a monthly alimony if to serve a short of one year only. This contradicts the prevailing concept and social justice for which the national pension system is directed. Second, the system would be vile since it did not filter the context of other pension beneficiaries. This means that they may exploit a dual receipt of pension, which doubles their retirement income and causes the social injustice in terms of public welfare. Even for the unworkable scope, e.g., a retired assemblyman, the pension would purport to ensure a basic level of human subsistence without the labor. The ideals would be disserved or perverted by allowing the same or more compensation for whose labor ceased. This multiplicity problem is now debated around the drafts of pension program, for example, the National Pension Plan (NPP) and Basic Subsidies Program of Aged People (BSPAP). In the case at matter, the alimony is ten times bigger than the BSPAP, and the NPP requires a contribution from the beneficiaries. Hence, the dual or multiple of eligibility obviously comes more serious in the PPNAM.

The alimony monies are rather gross in amount. According to the 2009 statistics from the National Pension Foundation, the spouses residing within Seoul are entitled to 1,100 and 1,008 dollars on a monthly basis since 2006 , who contributed an installment during 219 months and 218 months respectively (Chosun Daily, 2013). This means that 18 years of contribution of statutory sum in each month could only qualify them for as less than 1,200 dollars. In comparison, an alimony for the retired congressmen, which is set at 1,200 dollars, outpaces it. One day service in the national assembly may bring a more economic benefit than the earnest and honest middle class of Korea. The NPP now undergoes a downward adjustment from the public pressure, but the alimony for them would be adjusted upward as corresponds with the price index. This leads to the challenge about the public sensibility of justice, equity and equality (SEP: Economics and Economic Justice, 2013; Cooper, T., 2012).

\subsection{The Second Case}

In the second case, the Plan, around Mar. 2012, was designed to promote a social reproduction if the nation was in the face of radical decline within the birth rate. It was 
pursued by the national government without an exception and on no discriminatory basis. The government applied a scale to increase the subsidies amount, but it has made no significant effect on the parents since it was less effected (AECFP, 2013). The parents may commit their children in some time frame to the public facilities. Besides the subsidies, however, an additional expense falls within the responsibility of parents, such as that for the education or activities. More problematic would be a serious confusion and unpredictability in the floor of public facilities, which stems from the lack of standard, rules nor ethical guideline on the subsidies system (Korea JoongAng Daily, 2013). The system is entirely on the basis of financial contribution by the direct transfer of currency amount. This serves a distortion of system in an intense competition for cash, and undermined the public value of fostering service, the kind of utilitarianism, an expansion of public infrastructure, as well as a liaison or network concept in bridging the private and public for the maximization of happiness. A particular note on the increase of the Household Fostering Service would show a floating away of public commission and trust, but it merely expedited the private enterprises to exploit as their income source. A tremendous amount of budget actually made a lesser effect since the quality of service provision and cost management were neither officially nor institutionally controlled (Reichert, E., 2011). This factor baffles any more efficient outcome. The Plan also has a critical flaw which was failing to exercise the policy survey and assessment concerning the addressees. This failure is a principal culprit for the abusive and imprudent vagary of clients, "file first and wait to see." On this basis, the true addresses in need of public fostering service only could get in a secondary priority or excluded eventually from the benefit of service.

\section{Major Challenges and Factors to Implement}

\subsection{The First Case}

A problem of the first case lies in the fact that it contravenes the basic promise and frame of public pension system in that no installment was exchanged for the bargains of eligibility (Chosun Daily, 2013). This way of dealings is prevailing and basic on the kind of system, as we see in NPP, BSPAP, and National Pension System for Teachers, as well as one for other governmental employees. This point comes central that most of the conscientious people express their sentiment and get to be disgruntled. It aroused them that the social justice and equity was either in imbalance or undermined. Other problem lies in the vulnerable system of monitoring and feedback. As said, the exculpatory clause enters the scope on exemption or disqualification (SADCRRK, 2013). The causes are vast keep on the initial determination of eligibility. Nonetheless, the regular device to check a qualification needs to be strengthened. The chief of Association is able to ask for the submission of evidence to support their continued status as a beneficiary. However, it would be needed of mandatory as a matter of law. Other more enhanced system to ensure a continued check-up for eligibility would be desired.

The controversy about this system has not been just on the public, but surfaced as one of hyperboles within the political parties themselves (Chosun Daily, 2013). The Budget and Audit Committee of National Assembly (BACNA) prepared the white paper, which includes a reaction and resilience of the people in concern and dissatisfaction. The critical points in this paper would be same as briefed that the basis to pension benefit is stripped solely with the age requirement. The elements often factored as the standard of public pension system, such as income, assets, an employment years, had been waived. That would transgress the ideals of frame instituted in other occupational pensions or National Pension. The controversy became especially serious since they are norm creators and receivers of norm. The ethical dilemma within the conflict of interest as well as prejudice on their position power or privileges actually aggravated the public contention and criticism (Hicks, D., 2013; Cooper, T., 2012). This aspect was geared up by the media and public press, which heralded an informed disclosure about the issue. A short service assemblyman and the criminals upon the termination of prison terms would not be excluded which could be sufficient to question its ethics and social justice (Laureate Education Inc. a, 2013). A dual or multiple of receipt and too much alimony were also pointed out in the paper. One other critical flaw was illustrated that the system avoids the economic condition of national assembly man or his household.

\subsection{The Second Case}

We now turn to see the challenges and factors to affect an implementation of the second policy, which, amongst of all, could be encapsulated into three points of consideration.

First, the budgetary constraints distort the Plan and lead to a complex ethical or social justice dilemma. On the last day, 2011, NASK approved an increased sum of budget from the governmental proposal covering the subsidies for the 0-2 year children (AECFP, 2013). This social benefit was fixed in a scheme over the years whose income ranges as lower than 70 percents. A scope of social welfare programs often have been pursued in a match with the local governments, which, as a corollary, requires an incidental local budget in the process (Korea JoongAng Daily, 2013). As the Plan was released on public notice, new demand increased dramatically and the required budget amount doubled. The national conference of city majors and province governors forecast an increase from the 50 percent household to the point around 70-80 percents, who commit their baby for the care of Plan facilities (2013). The local governments, largely troubled from the unsound budget and often vulnerable in terms of financial independence, have to undertake the Plan by creating a heavy debt and owing to 
the absence of sufficient intergovernmental coordination in advance. Jong-bum Lee, who is a chief administrator of local governments, lamented, "The subsidies for the Plan would be drawn in the form of matching funds, and usually in the half-to-half ways between two governments en toto, which depends on a specific condition of respective local government. NASK miscalculated the number, 30 percents households disserved in the past, and expected 3.7 million dollars to meet the demand. The new demand unexpectedly exploded that the financial burden of local governments amounted as high as 7 million dollars" (2013; Reichert, E. 2011).

The National Planning and Financing Department and other agencies shared an expectation that the budget basis will be drained within about 10 to 17 local governments around June and July, 2012. One Seocho-gu officer said, "Seocho-gu would be most serious. Other adjacent prescient would be supported with 60 percents share from the central government, but ours would be as less as 30 percents. This means that we will have to discontinue in this June because of the financial unfeasibility" (2013)

One rank officer of local government also deplored, "The residue from the last year was officially transmitted to the local government in May. However, the monies already was planned to complement the shortage of NPPAP and other public projects. Then it would not serve any fiscal deficit from the FFCP. Any more drastic measure only could save the current dilemma of fiscal impasse" (2013).

FFCP was designed absent any consonance and prior consultation with the local governments, and processed in the NASK. This anomaly from such unilateral initiative should be put on the shoulder of that responsible dimension, i.e., a central government.

As the FFCP began to be implemented, over new five hundred public facilities had been recorded through only two months period, Dec, 2011 and Jan. 2012. Only 35 were national and public facilities, but other 438 private ones increased in number by twelve times to the former Plan (2013). This course of multiplication also went same in 2005 and 2006 provided that the subsides amount on the basis of facilities diminished as well as that on the children basis increased. We can chart a same mode of progress that the private or a free home fostering form multiplied, that a competition to induce the children intensified, while the pursuit of commercial interest swaying as unethical. The national or public facilities got marginalized in number as less in 5.3 percents, and the private facilities predominated on the provision of service. The policy goals from the Plan had a central focus on the expansion of subsidies amount, and the increase of infrastructure or facilities was on the list in policy items, but set aside because of an insufficient budget. This critical flaw virtually paralyzed the Plan, and well calls upon its halt or suspension. A focal attention from the consumers of Plan would rather sees a trust and credibility related with the quality of facilities and adequate management or supervision. Given the burden from an additional expense, the Plan's primary goal would less effectively work (Cooper, T., 2012).

A use rate of fostering facilities for the 0-2 year children amounted to $50.5 \%$ in 2009 , which allows a third spot in the OECD statistics. This rate is too high in factors from the OECD recommendation that $30 \%$ would be adequate and the home breeding would be a better option below the age two. Korea surpassed the recommended rate four years ago. Only Holland and Sweden outranked Korea by 83 and 66 percents respectively. Their case would be distinct that 72 and 76.5 percents of parents are working while Korea shows only 29.9 percents of parents on the employment status (Korea JoongAng Daily,2013). This statistics shows that no strong reason afforded a ground for such high rate of subscription to the public fostering service in Korea. This trend principally seems to be caused from the unsavory rush of parents, who perhaps would be apprehended with the intuition of free riding and any hallucination of loss. No genuine concern seems to be posited on the committing parents. This trend is certainly inimical to the most seriously interested households, say, working mother homes. The system legally misled a consumer's classification by exclusively relying on the number of children for each facility, as well as the "first come first served" dealings. The housewife mother homes can petition earlier to frustrate a working mother. From the launch of Plan, their propensity got worse to consume the whole hours as maximum as possible, yet to be legally entitled to them (AECFP, 2013).

It is a postulate dominantly accepted that an affinity and pathos created around the earlier years of children around 24 months is determined to form a healthy psychological ego, i.e., social attitude, personal emotion, and trust relation in later years. A stable affinity and pathos in these years also affect to develop their brain or mental capacity, and autonomy as well as maturity of an ego later years. Otherwise the children would suffer from the mental dip about an aggressiveness or brutal hostility and degradation of self-confidence or sense of trust. Any best way to increase the affinity and pathos of children is a mother's hug that needs to be frequented, and some intimate contact with a biological mother. Ericson, an influential author in this area, particularly stressed the importance of early childhood and intimate relationship between the mother and child. Myoung-hee Ahn, a professor of psychology in the Seo-Gang University, also adverted,

"The mother plays a role to bridge the world and child in his or her earlier years. The children can develop the character and intuitive power to overcome the frustrating pressure or strains. A lack of this phase in earlier years often causes his self-suspect and distrust of the exterior world. Korean tradition once would be a paradigm that the western household worshipped to follow. That now is no realities here" (2013).

One public employee, named Hye-jeong Choi, served five years to provide the fostering assistance and said,

"I am discontent with the Plan. The children committed to my care, all through the daytime, are crying for her 
biological mother, and the apparent context of subsidies benefit usually incurs an impulse of non-working housewife to ask for long hours of care." She now works in the Seoul Child Facilities, which operates from 7: 30 in the morning through 7: 30 in the evening."

A tax abuse and additional expense burdened on the parents also pose the challenge. Some of the fostering facilities enforced a wholesale increase of expense for 3-4 year children although they focused on the five-year group. This practice urges a follow-up investigation and adequate policy response at the national scale. The government granted subsidies in sum on the basis of law, and the facilities often should neither trade off that nor even increase the cost from other justification (AECFP, 2013). This could make a policy effect by never reducing the pocket expense of parents and because of the tremendous amount of budget, i.e., 1.2 billion dollars. Their basis to increase an incidental charge is ambiguous, such as the heating cost or event expense. Nonetheless, the local governments, a principal actor to supervise the system, have neither performed any research nor initiate a supervisory command to ensure the transparent administration. This status, highly irresponsible and neither fiduciary nor ethical, forecloses the initial ambition of this plan, which would practically be obvious over ten private facilities at the urban Seoul (Cooper, T., 2012).

The fostering administration often does not function in public trust and credibility, which would likely be from the unethical and interest-driven owners. A short minute of care legally entitle them to claim the subsidies so that they often prefer a housewife children rather than those of working mother. It is highly selective that an easy access to the facilities was baffled. As the quota of children increases, the quality of service would degrade and a workload of fostering teachers gets tougher. The benefit ascribed to each party also shows that the policy grossly favors the fostering facilities. In dollar amount, it is dispensed away with 800 for the facilities, 400 for the parents, and 200 for the fostering teachers (Korea JoongAng Daily, 2013).

Finally, a geographical disparity can undermine the equal justice of this policy varying with the quality of fostering teachers and their service provision. The government implements a guideline on the work frame in time, which is from 7: 00 in the morning through 7: 00 in the evening. If the work frame would change to extend, the paper work of fostering teachers would add making it some twelve hours cumbersome work. Their compensation might be halted in some cases, which also got worse depending on the fiscal state of each local government. The fostering teachers tend to leave a deprived region for the high income locales, which often are populated with the working mother houses. A reform alternative to improve the facilities is dispensed by the terminal officers or owners which undermines the sense of pride and personal decency. However, they do not have an effective means to raise their political voice. That is because the fostering teachers are not represented collectively unlike the owners of facilities. The unethical owners often see a headcount of children as their income source, and some fostering teachers are incompetent or uncommitted. This context could impact seriously to the disadvantage of children. For the children of 0- 2 year range, a shortage in the supply of teaching servants poses the greater challenge, particularly for the locales of province and in the agricultural area. In case of Chung-chung Province, the necessary fostering teachers would be around 7,000 from the whole quota of 600,000 , while the practical force is 6,000 in number (2013). For this reason, the quota often was not satisfied from 80 percents and even lower as 60 percents in the agricultural area. Three children would be assigned to match one fostering teacher, but the context is not being implemented as schemed. One local employee of government urged, "Any special policy response needs to be shaped. Otherwise, the ambitious plan may be accused of perpetrating a serious discriminatory consequence" (2013; Reichert, E., 2011). Thirteen facilities among fifteen in Young-dong failed to recruit a requisite number of fostering teachers. Some provinces enacted to reimburse a special compensation in some small sum, but likely effects less.

\section{Recommendations and Outcomes}

\subsection{The First Case}

BACNA reported a policy suggestion to remedy the identified problems, which is encouraging and on progress. They perceived a controversy in competing policy goals, i.e., integrity and sanctity of congressmen as the constitutional agency and the acceptable design of system. They are required of the high standard of position ethics from the Constitution, statutes and internal ethical code, but the support of senior members, who could be economically deprived, is lacking. This context was responded, as said, by an enactment of the pertinent laws across the developed countries. Korea has already entered an advanced status, which requires exploring the need of system more seriously. It increases a point of persuasion provided that the nation has long afforded an affluent public pension for the military personnel and government employees. BACNA adopted the alternative to go with the current system as is, while simultaneously launching the task force to be responsible for a revision. The revision project would begin with the collection of ideas and opinions from the incumbents and former national assemblymen. A first priority was suggested that the administration unit of NASK reviews the merit of sliding scale as well as the linking possibilities with the NPP (Chosun Daily, 2013). Their long term ideals would remain as same that it is required and ethically rewarding to support a financially vulnerable and aged assembly man. It comports with the requirement of social justice for their contribution and devotion to the nation. Therefore, their viewpoint on this agenda basically agreed on the fundament of peer pension system, but urged the need of political process for the popular support and sense 
of justice, as well as the equality and equity. The reform voice is not solely for the BACNA, but major political parties are active to modify the system toward a more reasonable one (Cooper, T., 2012). Three revision proposals are now pending and assigned with the responsible committee. This development would fall in a sharp contrast with the passage of Act in 2010, which was a one day process.

\subsection{The Second Case}

Most impending is that the policy makers have to be perspicacious in decreasing the quandary of policy abuse. It would be the way of fiduciary duty owed by public officials how to be faithfully committed to the foster and care of children. A mere spending to grant and subsidize would vitiate the values on human right, liberty, as well as social justice (Laureate Education Inc. b, 2013; SEP: Positive and Negative Liberty, 2013; Universal Declaration of Human Rights, 2013). As surveyed, 0-2 year children would be more desired of home fostering, and many countries, in accordance with the OECD suggestion, institutionally support the mode of financial benefit. The Korean system, on the other, enforces a unitary scheme of public facilities, which can bring a discriminatory effect on the households. In consideration of the concerned parents and children, children over three years could be grouped for the fostering service. The national programs in this kind need to be designed carefully, which requires referring to the professional advice and adequate public forum. While we share the merit of subsidies in the cause of welfare expansion, the government will perform well if to reevaluate the scheme for the home breeding of children below 2 years in age. The present system limited an access to the public subsidies available for the second class in the government wealth classification code if the household opts for a home breeding. It has to be revised that all classes can choose without any disadvantage between the home breeding and use of public facilities. This would serve the equity interest and would comport with the OECD suggestion (Cooper, T., 2012).

A serious assessment of ill effect in the prior year was not made. Until 2011, the subsidies were dispensed exclusively to the users of public facilities. In 2012, the revision rather extended the amount of subsidies and avoided an acid criticism about the discrimination of home breeding (AECFP, 2013). A view announced from the Seoul $Y M C A$ is echoing,

"As the children under the age of two would be done better at home, and this being in accordance with the OECD guideline....The public service would pertain to the group of three to four years, which requires the system to be transformed from the subsidies to some national child alimony" (2013)

It is fortunate that the Department of Health and Welfare (DHW) accepted this view to allow the parents of 0-2 year children an option between two ways of dealings. It would also serve the equality and convenience of system to provide the voucher system where the parents can use only in case of needs. A tax benefit needs to be afforded in the purpose to boost a birth as well as to meet the fostering needs of women. A tax deduction on the educational expenses also would be helpful. On other basis, it would make a public good if the policy can shift to be founded on the disparate income frame and scaling system. The national or public nature of facilities would yield a fair and impartial administration in experiences, and the workplace facilities would be urgent to improve the system. According to the Nov. 2010 report from the government, it obliged the statutory size of firms to provide the workplace fostering facilities, but four of ten would not satisfy that requirement (2013). The government keeps their names confidential to avoid the public criticism. The Civil Society on the Justice of National Economy, one of most active pressure group in Korea, claimed its public disclosure in the last June, but the response has been inattentive in any short comment, "It would jeopardize the property rights of citizen." This interaction simply shows a historic contention between the liberal and social state paradigm. In the statistics, 236 among the whole 576 classed into the scope of statute failed to meet a legal requirement, which includes a workplace with more than 500 employees at total or more than 300 female workers. In conditions as the safety issue or lack of space, they may alternatively bear the expense to foster the children or designate other exterior facilities. The above 236 firms neglect on these duties, and the aspect of penalty or disciplinary measure has to be reinforced relying on the requisite legal provisions (2013).

\section{Philosophies and Theories}

The cases described above show a typical dilemma about the classic idea of government as well as the modern national paradigm in pursuit of the social justice or welfare. The first case can be ethically questionable if the lawmakers could enact a law to their self-interest. In the modern ethical term, the pension plan possesses a quality of contention possibly in derogation of the right ways on the conflict of interest (Hicks, D., 2013). The legislative power is expected to operate under the separation of powers principle (SPP), hence, this traditional adage of legal principle can be reminded to respect. As incorporated into the Constitution, the standard as to regulate their conduct and of ethics would approach as powerful as in the cases, such as the prohibition of ex-post laws or self-incrimination. Otherwise, even the natural law theory could also mandate to conform their conduct to the inviolable concept of justice. For example, it is self-evident that nobody can enact the laws for himself in any discriminatory or specific ways to dispose. The laws need to keep on the essence of justice in general as well as in the form of abstract terms or prescriptions. A classification and way of dealings are required to be impartial and unbiased so as not to disparage the intrinsic of executive power (Kranich, N., 2007). Hence, it is strictly forbidden to enact the kind of dispositive law, 
but the acts should allow an interpretive leeway expected to operate within the province of executive power. That assures, as a way of inter-branch check and balance, the ideal of separation of powers principle and against any arbitrary abuse of vested powers by one branch of government. The vehicle of SPP, hence, could enable a "division and loyalty" to the popular democracy.

We often say the "divide and rule" axiom in the traditional operation of labor union and in the imperialistic ways of ruling for the subject states. The idea shares a similar attribute except that the public administrators have to be loyal to their sovereign and popular will. The public administrators are no longer placed to the role and responsibility on the successive or hereditary basis. They are elected by the people and may be appointed by the representatives of popular will. That is the only basis if they could be empowered and carry their constitutional or statutory power. They are, in this respect, required to owe the kind of fiduciary duty and act on trust to serve the people in any faith, professional competence and capacity. As Cicero, a Roman philosopher on the ethics of ruler and social justice, said, "Justice is a fundamental element to be ensured of the rule or governance, which is only way leading to a human solidarity" (Laureate Education Inc. a, 2013). While the pension plan can fuel a controversy in light of the liberty and SPP, it also can evoke the dated notion of social justice and ethics of public administrators. Bentham perceived the importance of new thinking about a rule, its ideals, understanding, network, system, and organization. He offers a philosophical foundation for the modern positive state on the legislation and new covenant of public administration to share the revolutionary spirit (Audard, C., 1999; Postema, G. J., 2006). His utilitarian conception and theory could contest, in tenet and ethical requirement, the right ways which the NASK had to opt for. His pursuit to maximize the individual happiness would be sublime for the administrators to bear in practicing their official duty. His free rider's thesis is interesting which could well discourage this faithful public theorist.

As outlined, the pension plan led to a high likelihood of public dissatisfaction and unhappiness about its sudden protrusion, hastened progress into the act, lack of public forum, insufficiency in provision and inadequate frame to find the eligibility, as well as high amount of subsidies. The goals and purpose triggered by the pension plan, however, could be verified to have a plausible ground. It was planned to support the great nationals who could not afford their lives in later years (Kranich, N., 2007). A fiscal feasibility may be sensible in the purview of ordinate treasury and apparently costs less a burden. An occasion of incidents developed in the NASK over the decade, however, proves in other way that several of such self-motivated measures frustrated the citizenry. The civil monitor group in Korea thankfully charted and reported to increase the public awareness. Notably, the group of assembly men have long years voted to increase their compensation under the circumstances where the national economy had staggered, the unemployment of youths disrupted the society, and the citizens were pressured so much that yielded the highest rate of suicide in the OECD statistics. They often showed the tendency to side their peers in the incident of justice on the arrest of person, who could, then, claim his constitutional privileges and immunities as a national assembly man. They should never be a housebreaker or highwayman whom Bentham made a wry wit about and who could stall the ethical and minded public administrators as saddened (Audard, C., 1999; Postema, G. J. (2006). They seem a due cause to institute the Plan, which complies with the comparative illustrations of developed states. The practical aspect of Plan, as suggested, could be reexamined in the end to create a supportive ethos of people.

FFPC was pursued in the spirit of social welfare and in order to promote the birth rate of nation. The social justice and equity, however, would posit a serious challenge as we detailed above. It does neither involve the conflict of interest nor ethics of congressmen in any conspicuous dress, but the redistribution of resources and wealth could possibly be misdirected and in the vein of structural or implementation flaws (Hicks, D., 2013). Most problematic is the present context of progress that a true beneficiary could be discriminated in the interest of facility owners leading to the ineffective consequence and contravening the intended goal of service. The equity, most closely related with the whole scale of social justice, would not be operated as deviated from the expected trajectory of Plan. The housewives have grown in number to exploit the benefit of plan as a primary class of beneficiary so that the working mother home, a target class of the Plan, was set to be secondary since the committed care requires more hours in terms of work demand. From the libertarian view in clan on the original freedom and property right, the welfare expense in this type would not be supported. They would entertain their ground to see no legitimate basis to spend the tax income and public funds without any key public use, such as police and national defense service. The positive liberty concept, however, suggests its role more affirmatively that the working mothers can be enabled to exercise their function and liberty with the welfare assistance (Crocker, L.H., 1980; SEP: Positive and Negative Liberty, 2013). They can work thanks to the public aids, and can manifest their capabilities, talents, and economic activity in freedom. The negative liberty or equal opportunity from the least involvement or less regulation of state could not reach this dimension. The context of controversy also reveals the concern of equality that the functional equality, implored by Dworkin and Sen, could be served if to be compared between the working mothers and unmarried maiden (2013).

The government exercised a classification to serve their policy goals in the benefit of household, which has the intended range of children, i.e., 0-3 years old. This brings the consequence of unequal treatment among the citizens, which can possibly abridge the equality of resources and 
opportunity. The "first principle," in the Rawls proposition, can see its way to the complex equality for the aids and grants in the cause to restore the justice. The "veil of ignorance" in the Rawlsian understanding could be posited about the deprived and child burdened household incidental to the working mothers. They are economically vulnerable, but could contribute to the increase of birth rate and economy or wholly for the social reproduction. The idea or concept can be shared in the same strand when the developed countries boost the developing counterparts by aids and grants, which Rawls and the current structure of WTO espoused as their economic justice (SEP: Economics and Economic Justice, 2013). The context of interplay would upgrade their function and contribute to the material welfare of humankind as well as the increase of world economy. This scheme on the social justice would be perceived as ambition-sensitive as Dworkin elicited. A retreat to merely an endowment-sensitive approach of equality would lead to any intolerable waste of working force and huge sojourn of human resources.

The equity or equality requirement may be highlighted by pointing to the geographical terms of nation. A fiscally deprived local government may suffer the minimal operation of fostering facilities which marginalized the service in a specific region. This would incur a great potential to deprave the legitimacy of Plan, so that the government is required to elicit the standard as well as to develop the revised scheme. It could be on feedback from the initial implementation period of Plan. The supervision and monitoring process need to be enhanced and be controlled to remove the chance of owner's unethical or contradictory commitment. The nursing teachers would be a precious actor to perfect the Plan. The government should prevent an intermediary exploitation of owners or managers, increase and maintain the quality and faith, and procure a requisite number of teachers to fulfill the demand.

\section{Concluding Insights}

\subsection{About the Ethics and Responsible Administration of the Collegiate Body}

The rapid context of globalization and geographical compression may be enabled by the technological advancement in the new millennium. I believe that this factor transformed the mode of governance where the collegiate body would penetrate the differing polities on the universal basis (Cooper, T., 2012). Now the people, or global public, perhaps would be less attracted by the political or economic theories, which, I suggest, had exacerbated the polities to their own way. The Orient and West also had long been deemed heteronomous between the western liberals and communists or feudal Orientalism. The impact of e-technology, as a most notable influence, now affords the opportunity to share and sense in any common attribute of humanity or society. Now the ethics or social justice, which is, in many subtleties, intimate, delicate, and applied beyond the established formality of western intelligence, can appeal not only in the national politics but also in the international plane (Laureate Education Inc. a, 2013). We can encounter a usual scene of summit in the meetings who exchange their personal value, perception and administrative ethics.

That would often not be the case when we consider the most universal body, i.e., national assembly or congress. An interchange in this domain may be in the network or liaison, but could not be leveled to the context of summit. Particularly, the way of executing their constitutional duties would be rather different as pointed out. For example, anonymity in their vote could render them even less responsible than the executive officials. The two issues discussed above expose a very basic contrast across the self-enactment, self-interest, social welfare and justice, positive liberty, as well as the human rights to a decent condition (Donnelly, J., 2013; SEP: Human Rights, 2013; Universal Declaration of Human Rights, 2013). The first case involves a classic notion concerning the potential abuse of power as coupled with the social welfare of target group. The second case deals with some most enhanced science or reasonableness of the social welfare program. Both issues actually sensitized the Korean people in a great concern and interest than any other serious economic issue. This implies that the netizenry and people in this new millennium are largely disposed to track intimately on the public administrators who long enjoyed an insulation and independent nobility. The trend may go similar with the socialist elitism of Congress or communist parties, and converge as subject to the public monitor or critical eyes. However, the ethics of them were not dealt in any coherent manner which factors the attributes as a collegiate body. I suggest that the Cooper's model may serve an individual member of collegiate body at this point of time, and hopefully expect for further studies more suited to the ethics of collegiate body (Cooper, T., 2012). Both issues actually disclose a square aspect of ethical failure to pull down the public image of NASK. Behind the controversy and public disappointment, we regret if they might neglect on a due regard to the required ethics. This could have been ameliorated if he or she individually and seriously assessed the problem on the kind of Cooper's deliberation. The attribute and quality of organization also seem to matter in terms of "institutional inertia" or amok, which requires any systemic studies of ethics and public administration concerning the collegiate body (2012).

The ethics and social justice are one of sensitive topic for the contemporary administrators and global public. For the material conditions have improved, this theme poses an aspect of serious challenge to attract our attention. The contemporary literature in this field had been dealt mostly with some philosophical studies, practical point of public administration, and some of efforts on theorization or design approach. The outcome of this less exposure would lead to the lack of working frame to analyze more systemically for the different nature of public organizations. 
While the Cooper's ethical decision making model shows the mental stage to deliberate on the ethical dilemma and challenge, it could possibly possess a universal quality as the design of ethical decision making process (2012). However, it is highly generalized to neglect on the specific nature of public organizations. I would like to withhold looking into the private or for-profit organizations since the theory or metaphor with the public ones would properly subdue the minimal nature of their dealings. Given the Cooper's analysis and approach provides a good model in the aspect of formality and mental progress about the specific public administrators, it is also necessary to substantiate the quality of ethics or social justice issue in terms of the attributes of public organization (2012). In this standpoint of view, I intend to make a distinction between the bureaucratic nature and collegiate body of public organizations. There are a scope of public organizations in the different nature, which maintains a bureaucratic work structure, notably the executive branch of government, foundations, charity organizations, public schools, and so. There could we find the collegiate form of organizations, such as congress or national assembly, public commission or council, consortium on the public project, and etc. The quality and attribute concerning the interplay of ethics or social justice with the collegiate bodies could be clarified in several aspects against the bureaucratic type.

First, the organizational members generally would enjoy the equal status and competence that a complexion or aura of ethical issues distinctly would not arise from the context of command and obedience.

Second, the organizational members often undertake an important role and positional power as a decisional body, who would be to leverage their ethical requirement more sternly in some cases, but as more softened in other cases. Both cases discussed above could be viewed in the latter light.

Third, they would be a norm or standard giver and simultaneously a norm or standard receiver, who has to respect the ethics codified or required in any form. They could be plenary to regulate their conduct, but the tradition and social attention would interact besides their conscience and personal quality or integrity (Maccallum, G.C., 1993). The specific context of norm formulation, for example, anonymity in the vote, could have a potential to be resilient in producing the socially desirable ethical code. In response, we may reinforce the stricter scheme about the kind of name-designated enactment, name-disclosed vote, and the intensive hearing session for the sensitive social welfare program as well as the public forum indispensable with the agenda on conflict of interest, and etc.

Fourth, they perform their job responsibility on the ad-hoc basis in many chances that the ethical requirement would normally be less serious nor challenging than the employees in bureaucracy. Therefore, I consider that the standing status of organization would be more a factor in distinction when we consider the ethics of public organization. For example, the panel would be an ad-hoc basis arrangement while the appellate body staffed with tenured judges and of standing nature would be seen otherwise in the context of WTO.

Fifth, it seems relevant concerning the ways of ethical process whether the organization is governmental or entitled to the constitutional privilege. The non-governmental organizations of public nature would share the attribute in an intermediary status between the private organization and governmental branch. Given the constitutional privilege, the national assembly, for example, would face with a distinct body of ethical practice on the tradition and constitutional expectation. For example, it could be a virtue for them, who would be more readily disclose the public truth in the Floor and which is other than the ranked bureaucrats or executive directors. The philie buster could also be viewed not strictly unethical, although we see it undesirable in some cases. Other governmental organizations, however, and across the jurisdictions, tend to be governed uniformly by the centralized statute or decree on the ethics and responsibility as a public officer (Laureate Education Inc. a, 2013).

\subsection{From the Econo-Political (West) to the Ethics or Justice Discourse (Orient and West)}

The two cases exhibit the typology of western thought between the liberal and social dualism projected over the scope of disciplines, i.e., politics, economics, sociology, law, and so (Murphy, A., 1998). The cases also exhibit a typical burden with which the public administrators, over the long centuries or decades have been disposed as challenges. The two cases would perhaps be irrelevant with the locus of nations, say, if to be west and east. For example, the spoils of victory in the $19^{\text {th }}$ America would still be on vestige and ethically challenged by some of public views. The Russia Mafia or Princelings in China over the decades would also show a dilemma involving the conflict of interest in any grand scale. The social welfare policy also could be shared in the communist states, and China notably intensifies the liberalization of national economy within the socialist basics (Hunt, L., 2008). They may restructure a perfect, but minimally afforded social welfare due to the materialistic incapacity. The liberal western states also struggle with any adequate extent of social welfare policy. Hence, the two cases are prone to seriate the wake of history and hemisphere on earth, which drove us to meditate on the ethical aspect of academic thinking. I consider the ethics and responsible administration studies in prongs, possibly with a sharing of common breath between the West and Orient, as well as the communists and liberals. The traditional frame is dominantly western, hence, econo-political to implant. Now I consider, however, that the need on this intellectual exposure could be said of a tradition or basic, merely a backdrop or in the least practically not arguable. We may impeach an evil state on the human rights violation, but never condemn them since they are a communist regime of national economy or so (SEP: Human rights, 2013). Notwithstanding the famous 
word, "demise of ideology," we now generally agree on its flip side, but some of new trends in our everyday lives.

Reverting to the cases, we suppose that the rulers in power should be on some ethics about the conflict of interest, and that the social welfare program could lead to the positive liberty or functional equality and the kind of substantive justice (Laureate Education Inc. b, 2013; SEP : Positive and Negative Liberty, 2013). Often the econo-political frames have been imposing to structure our intelligence, but the massive society or close context of public interaction on the e-technology, of course for many other reasons additionally, now defines the practical points of contention in other way. If only minimal improvement could be ascertained from the earlier century or past decades of Congress in both issues, the public now are more interested in their ethics, manner, motives of policy, and the kind of justice attitude. The contemporary society poses a multifaceted challenge of human condition and lives in dignity (Hunt, L., 2008). A progress to the modern civilian society enabled a materialistic prosperity in our living conditions although the awakened voice may claim an aspect of fundamental wrongs from the generalization and consequent amok from the unbeknownst or intoxicated leverage of massive general base or manageable citizens. They have a concern widely across the social justice or pain of discrimination, poverty and unemployment rate, stalemate of economy not to satisfy the population growth, as well as their income or retirement prospect in terms of the assets or pension. However, the modern structure of politics and economy has settled well making them to be a merely adaptive personality and to focus on their chores vastly. This constant tone and ethos in the lives of dominant class would be refreshed by routine exposure to the international controversies or idiosyncrasy from the politics, and national or international leadership or other exotic experiences. However, that would not entail a serious political or economic issue to disrupt their pleasant personal domain (Murphy, A., 1998). If we now gradually acknowledge so-called G2 politics and the rise of Oriental power, we may be helped with some of useful insight from the standing Chinese leaders. In the hierarchy and rank order, the newspaper introduced three Chinese leaders, Xi jin Ping, Lee, and Hwang. The leaders had addressed his interest by illustrating a most influential book in his respective leadership. $X i$, as matched with his top national status, illustrated one Chinese novel titled Ordeals and New Plane and authored by the professor of Chinese Military Academy. Lee, as a second rank of leadership, was concerned about the national economy, and mentioned the book which frontiers the second industrialization on the fossil fuels toward the third of information technology (1998). Hwang shed a light on the insights and wisdom proposed by A. Tocqueville about the revolutionary social condition. China, besides her rising status in the world economy, is a most populated country. We now witness that the world becomes compressed to see a gradual congruence between the West and East or Orient for many reasons, for example, e-technology or some of decade or century enduring experience from the liberal or social democracy. The civilian wake of democratic governance has trained both hemisphere to share a common ground and openness to exchange. Despite the continued difference or contention at some extent, I like to suggest the ethics and social justice could be one of governing theme which the contemporary global public implicitly receives more than any other political or economic discourse (Laureate Education Inc. b, 2013). While, in the Lee's interest, his book can bear an intellectual insight and serve to cultivate the mindset or attitude of national leaders, it may be seen to the large public as some of applied restructuring of the current structure within the global or national economy. For $X i$, the Chinese novel would offer the soil and implied value or social compassion for that long history of grand nation, but might be nationalistic to be resilient with the common rationale for the global public. It would come little to influence that perhaps lacks a quality of socialism advocacy if the book is merely a novel other than any social science or professional book. Hwang's regard to the Tocqueville may contain a universal theory or viewpoint about the revolution and social condition. However, it could be limited to the worse political condition of China for the still lower per capita income, gradual income disparity between the poor and rich, and their prevailing adherence with the economic equality on socialism. Over the three cases for the incumbent leadership of China, we hardly find a book to advocate on the orthodoxy of communist ideology or politically impressive forge.

If we turn our attention to the western mode of developed countries, the econo-political framework devoted to the western industrialization perhaps would exhaust its all the genesis to make it the kind of stalemate. Nobody questions the precious idea of free market and financial policy to energize the national or international economy. The FRB has tried their best through the decades to vibrate the national and global economy, and the IMF as well as the World Bank could gladly take a part to cooperate and collaborate. We, the global public, however, could share merely in reticence, accomplice, nodding or support, as well as the general credence on their wisdom and theory. This attitude or intellectual perception would also be same about the modern political discourse. Now the Korean people generally do not think if any shift of governmental structure to the parliamentary system would bring any difference on the politics or their actual ways of living. They probably would be correct to know if the scheme is keenly related with the turn-out of modern democracy from the feudal system. The context would be said similarly as the second and third generation narratives in the economic transformation.

So I believe that the contemporary global public, in the mid of post-modern realities and besides some of distinct groups or individuals, would be vastly concerned of the ethics, social justice or responsible administration than the insipid reiteration of the property and freedom of contract generalization. An assembly man Choi, who is a floor leader of the National Assembly from Sanouri said, "Korea 
is now on 'excessive democracy' rather than its lacking or insufficiency," in response with the street demonstration of opposing party. This comment suggests some of truths that Korean public would detest a stereotype of political narrative on the democracy and freedom, but demand the professional ethics. They would be more sensitive to the social justice and pay a due regard to the responsibility of public administrator. Lee Kuan Yew, one respected charisma of Singapore, impressively addressed the Oriental virtue as distinct and precious through the long history (Postema, G. J., 2006). Eo-ryung Lee, a distinguished professor from the Ewha Womans University in South Korea, also emphasized, through his brilliant academic career, Korean and Oriental philosophy, the strengths of Oriental value, and predicted a new cultural primacy of Orient in the new millennium. He commented, "The first millennium had been the era of Oriental dominance in terms of material prosperity and cultural superiority." The second thousand years had been led by the Western power, who embedded the democracy and idea of free market in the world. The new millennium would be wheeled ahead by the Oriental influence where the ethics and values in the esoteric nature could be shared and expand into the universalized respect and followership (2006). For the importance of China, I like to revisit an above illustration pointing out that they imply their social minds except as basically variegated with their urgent need to administer their state developmental paradigm. Among the aspect of principle, I assess that they sacrifice the liberty interest in such trade-off with the equality adherence. The social justice and liberal conception of human rights would compete in China, but would probably find the point of compromise given the near future on any sufficient material conditions (Donnelly, J., 2013). It would also comply with their state foundation, i.e., Deng Xiaoping's conformed in the 1980's (SEP: Human rights, 2013).

That briefed, I suppose that the future academics would deserve a new and enhanced focus on the studies of ethics, social justice and responsibility of public administrator than any other times.

\section{References}

[1] A Harsh Response from the Citizenry Against the Passage of Alimony Act (2013, Jan. 6) Chosun Daily, Seoul, South Korea.

[2] Act on Early Childhood Fostering Program (AECFP), Korea Stat 12068 (2013).

[3] Audard, C. (1999). Anthologie historique et critique de l'utilitarisme, tome 1: Bentham et ses précurseurs (1711-1832). Paris: Presses Universitaires de France - PUF.
[4] Cooper, T. (2012). The Responsible Administrator. San Francisco, CA: John Wiley \& Sons.

[5] Crocker, L.H. (1980). Positive Liberty: An Essay in Normative Political Philosophy (Melbourne International Philosophy Series), New York, NY: Springer.

[6] Donnelly, J. (2013). Universal Human Rights in Theory and Practice, Ithaca, NY: Cornell University Press.

[7] Hicks, D. (2013). Dignity: Its Essential Role in Resolving Conflict, New Haven, CT: Yale University Press.

[8] Hunt, L. (2008). Inventing Human Rights: A History, New York/London: W.W. Norton \& Company.

[9] Kranich, N. (2007). Equality and equity of access: What's the difference. Retrieved July 10, 2008 from the American Library Association Web site: http: www.ala.com.

[10] Laureate Education Inc. a, (2013). Ethics and Social Justice "Equality and Equity: Applications" with Amanda Baker (ap proximately 6 minutes).

[11] Laureate Education Inc. b (2013). Ethics and Social Justice "Liberty: Applications" with Amanda Baker (approximately 7 minutes).

[12] Local Governments on the National Child Fostering Program (2013. June 19), Korea JoongAng Daily, Seoul, South Korea.

[13] Maccallum, G.C. (1993). Legislative Intent/Essays, Madison. WI: University of Wisconsin Press.

[14] Murphy, A. (1998). Reason, Reality, and Speculative Philosophy. Madison WI: University of Wisconsin Press (1996).

[15] Postema, G. J. (2006). Interests, universal and particular: Bentham's utilitarian theory of value. Utilitas, 18(2), 109-133.

[16] Reichert, E. (2011). Social Work and Human Rights: A Foundation for Policy and Practice, New York, NY: Columbia University Press.

[17] SEP (2014): Economics and Economic Justice. Retrieved Nov. 2. 2013 Nov. 2, 2013 from http://plato.stanford.edu/archives/sum2008/entries/economic -justice.

[18] SEP (2014) : Human Rights, Retrieved Nov. 2, 2013 from http://plato.stanford.edu/entries/rights-human/.

[19] SEP: Positive and Negative liberty, Retrieved Oct. 25, 2013 from http://plato.stanford.edu/entries/rights-human/.

[20] Supportive Act of Democratic Constitutional Rule in the Republic of Korea (SADCRRK). Korea Stat 12068 (2013).

[21] UN (2014). Universal Declaration of Human Rights 